\title{
Effect of Parents' Involvement Interventions in Speech Language Delay among Late Talking Toddlers in Egypt: A Quasi-Experimental Study
}

\author{
Farrag S ${ }^{1,2 *}$, Afolabi MO $^{3}$ and Rehab Abd El-Aziz El Sayed ${ }^{4}$ \\ ${ }^{1}$ Faculty of Nursing, Umm Al-Qura University, Saudi Arabia \\ ${ }^{2}$ Faculty of Nursing, Mansoura University, Egypt \\ ${ }^{3}$ Faculty of Infectious and Tropical Diseases, London School of Hygiene \& Tropical Medicine, \\ UK \\ ${ }^{4}$ Faculty of Nursing, Mansoura University, Egypt
}

ISSN: 2576-9200

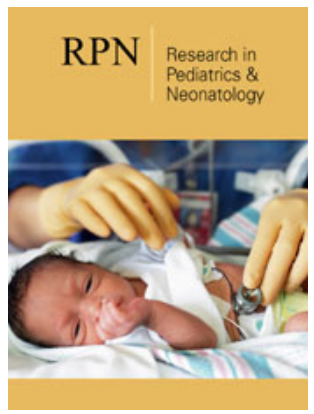

*Corresponding author: Farrag S, Faculty of Nursing, Umm Al-Qura University, Saudi Arabia

Submission: 㘹 May 13, 2020

Published: 眥June 19, 2020

Volume 4 - Issue 4

How to cite this article: Farrag S, Afolabi MO, Rehab Abd El-Aziz El Sayed. Effect of Parents' Involvement Interventions in Speech Language Delay among Late Talking Toddlers in Egypt: A QuasiExperimental Study. Res Pediatr Neonatol. 4(4). RPN. 000592. 2020.

DOI: $10.31031 /$ RPN.2020.04.000592

Copyright(C) Farrag S. This article is distributed under the terms of the Creative Commons Attribution 4.0 International License, which permits unrestricted use and redistribution provided that the original author and source are credited.

\begin{abstract}
Background: Speech language delay is a common developmental problem among Egyptian children. There is paucity of reliable data on parent involvement interventions in speech language problems and of communication disorders in Egypt.
\end{abstract}

Objective: We evaluated the effect of parent involvement in language development intervention programmes on a population of late talking toddlers recruited from local kindergarten schools in Alexandria, Egypt, using interaction-promoting strategies which encourage children to take turns in a conversation, ask questions and wait for a response.

Methods: Seventy-nine mother-child pairs were randomly assigned into an experimental group where a validated Language Development Survey (LDS) was administered while study mothers assigned to control arm had routine care according to kindergartens policy in Egypt. Pre-and post-intervention assessments were conducted on all domains of the tool.

Results: Approximately one third (30.9\%) of the study children in the experimental group had severe language delay pre-intervention and this decreased to $16.2 \%$ of children post-intervention. On the other hand, less than one quarter (18.2\%) of the study children in the control group had severe language delay pre-intervention, this increased to about half $(54.5 \%)$ of children post-intervention $(\mathrm{p}=<0.043)$.This showed that significant expressive language gains can be made by pre-school language-delayed children, through group parental-based language intervention.

Conclusion: Findings of this study suggest that parent involvement had positive outcomes in terms of language development in their late-talking toddlers. The study supports the concept of parent involvement as a viable model of language intervention for promoting short-term developmental progress in latetalking toddlers.

Keywords: Speech Therapy; Paediatric; Nursing; Parent Involvement; Language Delay

\section{Introduction}

Talking is one of the most important visible developmental achievements of early childhood [1]. Given that ability to make intelligible speech and language is an important correlate of child's overall development and intellect, the diagnosis of speech delay is made when a child does not achieve this developmental milestone at the expected age [2,3]. Globally, the prevalence of speech and language delay in children ranges from 5-15\% [4]. In the United States and Canada, $8-12 \%$ of pre-school and 12\% of school-age children experienced speech delay [5]. In Egypt and many countries in the Gulf regions; paucity of data exists on the burden of this important early childhood disorder. Nevertheless, empirical evidence showed that the quality of language learning during these early years of life does not only impact significantly on the development of oral language skills, but also on later success in literacy [6,7]. Language problems may result from mental retardation, physical handicaps, hearing loss, neurological problems, or environmental deprivations [7]. It has serious sequelae that may persist into adulthood in terms of educational, social, and emotional development [8]. When children fail to develop normal speech at appropriate time, it is therefore not surprising that they develop 
psychosocial, emotional problems, beside the learning disabilities that might arise at later stages.

Communication development in the early years is closely linked with and dependent upon the input and stimulation received from parents and primary caregivers. When interactions between a parent/caregiver and a child are deranged, this places the child at risk for a communication disorder [9]. Hence, parents and caregivers play an important role in the early identification of language disorders. Parents and care-givers of children experiencing language delay are more likely to be reluctant in seeking medical advice at early age [10]. Four language teaching strategies have been identified by experts to improve children's language abilities. These are: prelinguistic milieu teaching, which helps children make the transition from pre-intentional to intentional communication; milieu teaching which consists of specific techniques embedded within a child's ongoing activities and interactions; responsive interaction which involves teaching caregivers to be highly responsive to the child's communication attempts; and direct teaching characterized by prompting, reinforcing and giving immediate feedback on grammar or vocabulary within highly structured sessions [11]. Early parent involvement programmes have proved effective and have positive impact on children's language outcome [11]. Reliable data on parent involvement interventions in speech language problems and of communication disorders such as Delayed Language Development (DLD) are currently unknown in Egypt [12]. This study was designed to evaluate the effect of parent involvement in language development intervention programmes on a population of late talking toddlers whose families could not afford specialized consultations in private clinics, and where these services were not available in public hospitals in Egypt. We hypothesized that implementation of language training intervention would improve the children's language development.

\section{Methods}

\section{Research design}

This was a quasi-experimental study adopting a pre/post-test intervention design to evaluate speech intervention programmes among late talking toddlers recruited from six private local kindergarten schools in Alexandria city of Egypt.79 mother-child pairs were enrolled into the study and followed up over a six-week period. The study participants were randomly assigned into two groups: experimental group and control group. The experimental group enrolled 68 mothers of children with language delay who were exposed to the interventions, and the control group consisted of 11 mothers and children with language delay who were exposed to routine care according to the national policy on kindergartens education in Egypt [13,14].

\section{Planned imbalances}

Researchers intentionally recruited a greater number of participants in the experimental group than in the control group. The allocation of participants to intervention was predetermined rather than manipulated by the researchers. Reasons for the imbalance include inaccessibility to specialist care, financial cost of care and a relative lack of interest by parents of affected children:
- Accessibility problems

- Financial cost

- A relative lack of interest

\section{Study population}

The study children were selected randomly from various kindergarten schools operating in two municipal areas of AlMontaza District of Alexandria Governorate, northern Egypt. With a population of approximately 1.2 million people, AlMontaza district is the largest district of the governorate [15]. Public education system in Egypt consists of three levels: the basic education stage for 4-14 years old: kindergarten for two years followed by primary school for six years and preparatory school (ISCED Level 2) for three years. The Ministry of Education is responsible for making decisions about the education system with the support of three centers: the National Center of Curricula Development, the National Center for Education Research, and the National Center for Examinations and Educational Evaluation. Each center has its own focus in formulating education policies with other state level committees [14].

\section{Study questionnaire}

A semi-structured, pre-tested questionnaire was adapted by the researchers from Language Development Survey (LDS) $[11,16]$. LDS was a vocabulary checklist designed as a screening tool for the identification of language delay in toddler age children. The LDS consists of a one-page vocabulary checklist of about 309 words, and a question asking about combining two or more words into phrases. If a 2-year-old child has fewer than 50 words or no word combinations; the child is considered to have a language delay. This tool was translated to Arabic language by the first author (SF) who is a native speaker of Arabic language. The translated version was back-translated to English language to confirm that the original meaning of the contents of the document was retained.

The LDS formed the main instrument used during data collection and this checklist was used for first time in Egypt. The 309 different words included in the LDS are arranged in 14 semantic categories (191nominals and 118 non-nominals). The categories are 'food'(32 words), 'outdoors' (11 words), 'toys' (11 words),'animals' (21 words),'body parts' (21 words), 'places' (8 words), 'household'(31 words), 'personal' (14 words), 'people' (15 words), 'clothes' (17 words),'vehicles' (10 words), 'actions' (56 words), 'modifiers' (31 words) and 'other' ( 32 words). All words within these categories can be classified into five categories as nouns, people word, adjectives and modifiers, actions and closed-class words [17]. The LDS total scores of all words were calculated and classified according to language improvement into three categories: mild language delay, moderate language delay, and severe language delay. Two sections were added to complement the LDS questionnaire: the first section focused on the socio-demographic characteristics of care-giver/ parent including age, highest level of education attained, marital status of parent/caregiver, occupation, family history of language delay and socioeconomic status (total annual income) that was assessed by using a combination of socioeconomic status scales [18- 
20]. The second section focused on the demographic characteristics of the study child which consisted of age, gender, birth order, number of siblings in the family and history of ear infections.

\section{Validity and Reliability of Adlapted LDS}

Given that this was the first time LDS would be used in Egypt, face and content validity was conducted for the tool to assess its appearance regarding readability, clarity of words used, consistency of style and likelihood of the target study participants being able to answer the questions satisfactorily. The adapted LDS was reviewed by a panel of five experts who had experience in instrument validation, drawn from the pediatric nursing (Nursing Practices) department of Umm Al-Qura University, Makkah, Kingdom of Saudi Arabia. The experts confirmed the relevance and appropriateness of the adapted LDS to Arabian context. They also agreed unanimously that essential elements of speech language delay were addressed adequately in the tool.

\section{Pilot study}

A pilot study was carried out amongst a sub-set of the sample population. This represented $10 \%$ of the study sample $(n=7$ mothers and 7 children) to test the applicability, feasibility, clarity and time needed to complete the study tool. Findings from the pilot study were used to modify the adapted LDS. The mother-child pairs enrolled in the pilot study were excluded from the main study. Eligible parents and children who met the following criteria were included in the main study: parents of children aged between 18 and 30 months; children aged 18 and 30 months with normal nonverbal IQs (according to their medical records); children with no sensory, motor or social-emotional problems; children who had little or no expressive language, defined as having a vocabulary of 30 single words or less; children who have not been diagnosed with a general developmental delay; children who did not have any past history of otitis media; and children who had not received previous speech / language therapy.

Data collection for this study was undertaken from April to May 2019. After the study purpose and procedures have been explained to the study mothers, each mother and child provided verbal consent that they voluntarily agreed to participate in the study along with their children. The study mothers were subsequently invited to attend an initial assessment and interview. With the support of a trained research assistant, each study mother was requested to mark on the list of words in the adapted LDS which her child said spontaneously, indicate if the child had language delay. Also, if the child used phrases and sentences, the study mother wrote down five of the child's best phrases, and completed the question items on parent and child's socio-demographic characteristics.

\section{Intervention Group: Parental Training Procedures}

The study mothers who were randomly assigned to the intervention arm attended group speech and language therapy training sessions twice a week, over a six weeks' period. Twelve sessions were held in total, with each session lasting about 45-60 minutes. In each session, specific language objectives were set for the mothers to work on at home. The mothers were asked to use daily routines with their children. Flexibility in approach to each language objective was encouraged during the sessions through the use of small group work. The main aim for the six weeks' period of the group sessions was to increase the child's linguistic ability from a single word level to the level of producing three-to-four word utterances. The study mothers were taught about language therapy application so that they could carry out the procedure and follow-up at home. Intervention effects were reported by nursery school nurses and the study mothers for a broad range of language measures, including vocabulary acquisition, development of multiword sentences, and speech sound development.

\section{Control group}

Study mothers assigned to control arm had routine care according to kindergartens policy in Egypt $[13,14]$. This consisted of a set of educational activities aimed at achieving the comprehensive development of the children and preparing them for school [14].

\section{Ethical considerations}

Ethical approval for this study was obtained from the ViceDeanship of Postgraduate Studies and Scientific Research, Faculty of Nursing, Umm Al-Qura University. Written permission to conduct this study was also obtained from AlMontaza Education authorities, Alexandria. Given the low risk involved in this study, verbal consent was obtained from the study mothers after informing them about the purpose and procedures of the study. Voluntary participation, confidentiality, anonymity and rights to withdraw from the study at any time were explained to each mother before starting data collection.

\section{Data analysis}

Data were analysed using Statistical Package for the Social Sciences (SPSS) version 21.0 (ed. Chicago: SPSS Incorporation. 2016). Descriptive and inferential statistics were performed. Continuous variables were summarized and presented using the mean $( \pm \mathrm{SD})$ for normally distributed variables. Categorical variables such as sex, age category, socio-economic status were summarized and presented using proportions and percentages, as applicable. The differences between mean $( \pm S D)$ of continuous variables were compared using independent Student t-test or Analysis of variance (ANOVA). The differences between proportions and percentages of categorical variables were compared using the Pearson's chi-squared $(\chi 2)$ test. The first step in the analysis was to divide the study children in each sample into six vocabulary size classes ( $<50$ words, 50-99 words, 100-149 words, 150-199 words, 200-249 words and 250 words or more). Next, the words on the validated LDS were re-grouped into five basic word class categories (common nouns, people words, verbs, adjectives and closed-class words), drawing on definitions suggested by Bates E, et al. [21]. Comparison between the control and the experimental group's findings was done to evaluate the effect of parent-involvement in language intervention/speech therapy program on a sample of late talking toddlers. Statistical significance was established when probability value (p) was less than 0.05 . 


\section{Results}

Table 1: Parents' characteristics.

\begin{tabular}{|c|c|c|c|c|c|c|}
\hline & \multicolumn{2}{|c|}{ Experimental $(n=68)$} & \multicolumn{2}{|c|}{ Control $(n=11)$} & \multicolumn{2}{|c|}{ Chi Square Test } \\
\hline & $\mathbf{N}$ & $\%$ & $\mathbf{N}$ & $\%$ & $\mathbf{X}_{2}$ & $\mathbf{P}$ \\
\hline \multicolumn{7}{|l|}{ Age } \\
\hline$<20$ years & 8 & 11.8 & 2 & 18.2 & & \\
\hline $20-40$ years & 43 & 63.2 & 7 & 63.6 & & \\
\hline$>40$ years & 17 & 25 & 2 & 18.2 & 0.491 & 0.782 \\
\hline \multicolumn{7}{|l|}{ Educational level } \\
\hline Illiterate & 3 & 4.4 & 0 & 0 & & \\
\hline Basic & 36 & 52.9 & 7 & 63.6 & & \\
\hline Higher & 29 & 42.6 & 4 & 36.4 & 0.774 & 0.679 \\
\hline \multicolumn{7}{|l|}{ Marital Status } \\
\hline Married & 53 & 77.9 & 10 & 90.9 & & \\
\hline Divorced & 8 & 11.8 & 1 & 9.1 & & \\
\hline Widowed & 7 & 10.3 & 0 & 0 & 1.391 & 0.499 \\
\hline \multicolumn{7}{|l|}{ Child's care giver } \\
\hline Biological mother & 56 & 82.4 & 10 & 90.9 & & \\
\hline Family member & 12 & 17.6 & 1 & 9.1 & 0.504 & 0.478 \\
\hline \multicolumn{7}{|l|}{ Occupation } \\
\hline Unemployed & 45 & 66.2 & 7 & 63.6 & & \\
\hline Manual jobs & 12 & 17.6 & 3 & 27.3 & & \\
\hline Professional jobs & 11 & 16.2 & 1 & 9.1 & 0.784 & 0.676 \\
\hline Family history of language delay & 19 & 27.9 & 5 & 45.5 & 1.373 & 0.241 \\
\hline \multicolumn{7}{|l|}{ Annual Income } \\
\hline Good & 11 & 16.2 & 3 & 27.3 & & \\
\hline Average & 48 & 70.6 & 5 & 45.5 & & \\
\hline Low & 9 & 13.2 & 3 & 27.3 & 2.778 & 0.249 \\
\hline \multicolumn{7}{|l|}{$\begin{array}{l}\text { Parent attended group speech and } \\
\text { language therapy training sessions }\end{array}$} \\
\hline 12 sessions & 32 & 47.1 & - & - & & \\
\hline 8 - 11 sessions & 28 & 41.2 & - & - & & \\
\hline $4-8$ sessions & 8 & 11.8 & - & - & - & - \\
\hline
\end{tabular}

The study children were classified into three phases of expressive language acquisition according to child age (22): first words for children at age of 12-<19 months; word combinations for children at age of 19-<30 months; sentences for children at age of $30-<48$ months. The socio-demographic characteristics of the study parents were illustrated in Table 1. Less than two thirds of the mothers $(63.2 \%)$ in the experimental group were in the age group (20-40 years). More than half of the mothers (52.9\%) had basic educational level, and more than three quarter $(77.9 \%)$ of mothers in experimental group were currently married. In addition, majority of the mothers (82.4\%) were the biological mothers of the study children. Approximately two thirds of mothers (66.2\%) were unemployed. Also, $70.6 \%$ of study mothers in the experimental group had an average annual income, according to the national socioeconomic status scale [20]. More than one quarter (27.9\%) of the study mothers in the experimental group had family history of language delay. Approximately half (47.1\%) of the mothers attended group speech/language therapy training sessions.

Table 2: Child's characteristics.

\begin{tabular}{|c|c|c|c|c|c|c|}
\hline & \multicolumn{2}{|c|}{ Experimental (n= 68) } & \multicolumn{2}{c|}{ Control (n=11) } & \multicolumn{2}{c|}{ Chi Square Test } \\
\hline & $\mathrm{N}$ & $\%$ & $\mathrm{~N}$ & $\mathrm{X}$ & \\
\hline Age (months) & & & & & \\
\hline $12-<19$ & 10 & 14.7 & 2 & 18.2 & & \\
\hline $19-<30$ & 54 & 79.4 & 7 & 63.6 & & \\
\hline $30-<48$ & 4 & 5.9 & 2 & 18.2 & 2.266 & 0.322 \\
\hline
\end{tabular}




\begin{tabular}{|c|c|c|c|c|c|c|}
\hline Sex & & & & & & \\
\hline Girl & 20 & 29.4 & 6 & 54.5 & & \\
\hline Boy & 48 & 70.6 & 5 & 45.5 & 2.709 & 0.1 \\
\hline \multicolumn{7}{|l|}{ Birth order } \\
\hline $1^{\text {st }}$ & 27 & 39.7 & 3 & 27.3 & & \\
\hline $2^{\text {nd }}-4^{\text {th }}$ & 31 & 45.6 & 6 & 54.5 & & \\
\hline More than $4^{\text {th }}$ & 10 & 14.7 & 2 & 18.2 & 0.623 & 0.732 \\
\hline $\begin{array}{c}\text { History of ear } \\
\text { infection }\end{array}$ & 29 & 42.6 & 2 & 18.2 & 2.377 & 0.123 \\
\hline \multicolumn{7}{|l|}{$\begin{array}{l}\text { Number of } \\
\text { siblings* }\end{array}$} \\
\hline $1-3$ & 27 & 65.9 & 5 & 62.5 & & \\
\hline $4-5$ & 14 & 34.1 & 3 & 37.5 & 0.033 & 0.855 \\
\hline
\end{tabular}

${ }^{*} \mathrm{n}=41$ for experimental group; $\mathrm{n}=8$ for the control group.

The demographic characteristics of the study children were illustrated in Table 2. Of the 78 children enrolled into this study, 53 (67.9\%) were boys. More than three quarter of the study children $(79.4 \%)$ in the experimental group were within the age group of 19$<30$ months. Regarding to birth order, approximately half (45.6\%) of the children were in range of 2nd-4th birth order and about two thirds (65.9\%) of them had 1-3 siblings. Less than half of children $(42.6 \%)$ in the experimental group had history of ear infection. The mean values of each word category relative to all types of vocabulary expression categories in experimental and control groups pre and

post-intervention, (according to the study mothers' reports), were illustrated in Table 3a. Post-intervention, the mean value (SD) of 'nouns' was (39.9 $\pm 7.8 \& 32.7 \pm 6.3)$ in the experimental and control groups, respectively $(\mathrm{p}=0.005)$. Similarly, the mean of 'people words' were $(4.4 \pm 1.2 \& 4.1 \pm 1.1)$ respectively in the intervention and control groups, post-intervention $(p=0.402)$. The mean value for 'action category' was $(4.1 \pm 0.9 \& 3.1 \pm 1.3)$ respectively in the intervention and control groups post intervention $(\mathrm{p}<0.003)$. The mean values of 'closed-class' words were $(5.0 \pm 1.2 \& 4.0 \pm 0.6)$ in intervention and control groups, respectively $(\mathrm{p}<0.007)$.

Table 3a: Comparing Experimental and Control Groups regarding vocabulary expression categories according to mothers' report.

\begin{tabular}{|c|c|c|c|c|}
\hline & \multirow[t]{2}{*}{ Experimental $(n=68)$ Mean \pm SD } & \multirow[t]{2}{*}{ Control $(n=11)$ Mean $\pm S D$} & \multicolumn{2}{|c|}{ Student`s t Test } \\
\hline & & & $\mathbf{T}$ & P-value \\
\hline \multicolumn{5}{|c|}{ Nouns } \\
\hline Pre & $18.3 \pm 4.4$ & $16.6 \pm 3.9$ & 1.138 & 0.259 \\
\hline Post & $39.9 \pm 7.8$ & $32.7 \pm 6.3$ & 2.902 & $* 0.005$ \\
\hline \multicolumn{5}{|c|}{ People words } \\
\hline Pre & $2.2 \pm 0.7$ & $2.1 \pm 0.4$ & 0.176 & 0.861 \\
\hline Post & $4.4 \pm 1.2$ & $4.1 \pm 1.1$ & 0.843 & 0.402 \\
\hline \multicolumn{5}{|c|}{ Adjectives and modifiers } \\
\hline Pre & $1.3 \pm 0.7$ & $1.5 \pm 0.5$ & 1.303 & 0.196 \\
\hline Post & $2.7 \pm 1.2$ & $2.8 \pm 0.9$ & 0.412 & 0.681 \\
\hline \multicolumn{5}{|c|}{ Actions } \\
\hline Pre & $1.8 \pm 0.5$ & $1.6 \pm 0.9$ & 0.983 & 0.329 \\
\hline Post & $4.1 \pm 0.9$ & $3.1 \pm 1.3$ & 3.042 & $* 0.003$ \\
\hline \multicolumn{5}{|c|}{ Closed-class words } \\
\hline Pre & $2.4 \pm 0.7$ & $2.1 \pm 0.3$ & 1.52 & 0.133 \\
\hline Post & $5.0 \pm 1.2$ & $4.0 \pm 0.6$ & 2.756 & $* 0.007$ \\
\hline
\end{tabular}

according to mothers' report.

*statistically significant $(p=<0.05)$.

Table 3b: Comparing Experimental and Control Groups regarding vocabulary expression categories according to nurses' report.

\begin{tabular}{|c|c|c|c|c|}
\hline & $\begin{array}{c}\text { Experimental }(\mathrm{n}=68) \\
\text { Mean } \pm \text { SD }\end{array}$ & Control $(n=11)$ Mean \pm SD & \multicolumn{2}{|c|}{ Student's t test } \\
\hline & & & $\mathbf{T}$ & P-value \\
\hline \multicolumn{5}{|c|}{ Nouns } \\
\hline Pre & $17.8 \pm 4.3$ & $16.3 \pm 3.7$ & 1.092 & 0.278 \\
\hline Post & $38.7 \pm 7.6$ & $32.1 \pm 6.1$ & 2.736 & ${ }^{*} 0.008$ \\
\hline
\end{tabular}




\begin{tabular}{|c|c|c|c|c|}
\hline People wo & & & & \\
\hline Pre & $2.18 \pm 0.69$ & $2.09 \pm 0.40$ & 0.42 & 0.676 \\
\hline Post & $4.31 \pm 1.19$ & $4.06 \pm 1.09$ & 0.653 & 0.516 \\
\hline \multicolumn{5}{|c|}{ Adjectives and modifiers } \\
\hline Pre & $1.27 \pm 0.69$ & $1.47 \pm 0.49$ & 0.922 & 0.359 \\
\hline Post & $2.65 \pm 1.18$ & $2.76 \pm 0.88$ & 0.537 & 0.593 \\
\hline \multicolumn{5}{|c|}{ Actions } \\
\hline Pre & $1.75 \pm 0.49$ & $1.56 \pm 0.89$ & 1.047 & 0.298 \\
\hline Post & $3.98 \pm 0.87$ & $3.19 \pm 1.29$ & 2.599 & $* 0.011$ \\
\hline \multicolumn{5}{|c|}{ Closed-class words } \\
\hline Pre & $2.30 \pm 0.67$ & $2.04 \pm 0.33$ & 1.258 & 0.212 \\
\hline Post & $4.8 \pm 1.19$ & $3.96 \pm 0.59$ & 2.287 & $* 0.025$ \\
\hline
\end{tabular}

according to nurses' report.

*statistically significant $(p=<0.05)$.

Table 4a: Expressive language development for children regarding their age, according to mothers’ report.

\begin{tabular}{|c|c|c|c|c|}
\hline & \multirow[t]{2}{*}{ Experimental Mean \pm SD } & \multirow[t]{2}{*}{ Control Mean \pm SD } & \multicolumn{2}{|c|}{ T test } \\
\hline & & & $\mathbf{T}$ & P-value \\
\hline \multicolumn{5}{|c|}{ First words total score for children at age of $12-<19$ months } \\
\hline Pre & $22.1 \pm 5.2$ & $20.5 \pm 0.7$ & 0.419 & 0.684 \\
\hline Post & $44.2 \pm 8.1$ & $39.5 \pm 0.7$ & 0.794 & 0.446 \\
\hline \multicolumn{5}{|c|}{ Word combinations for children at age of $19-<30$ months } \\
\hline Pre & $1.26 \pm 0.44$ & $1.29 \pm 0.49$ & 0.147 & 0.883 \\
\hline Post & $1.93 \pm 0.26$ & $1.57 \pm 0.54$ & 2.912 & $* 0.005$ \\
\hline \multicolumn{5}{|c|}{ Sentences for children at age of $30-<48$ months } \\
\hline Pre & $2.25 \pm 0.50$ & $1.5 \pm 0.71$ & 1.549 & 0.196 \\
\hline Post & $2.50 \pm 0.58$ & $1.5 \pm 0.71$ & 1.886 & 0.132 \\
\hline
\end{tabular}

*statistically significant $(p=<0.05)$.

Table $3 \mathrm{~b}$ showed the mean values of each word category relative to all types of vocabulary expression categories in the experimental and control groups at pre and post-intervention, according to the nurses' report. The mean values of 'nouns' was (38.7 $\pm 7.6 \& 32.1 \pm 6.1)$ respectively in the experimental and control groups $(\mathrm{p}<0.008)$.The mean values for action category mean were $(3.98 \pm 0.87 \& 3.19 \pm 1.29)$ in the intervention and control groups, respectively $(p<0.011)$. Similarly, the mean values of closed- class words were $(4.8 \pm 1.19 \& 3.96 \pm 0.59)$ in the intervention and control groups, respectively $(\mathrm{p}=<0.025)$. The mean values of word combinations for study children in the age group of $19-30$ months were $(1.93 \pm 0.26 \& 1.57 \pm 0.54)$ in the intervention and control groups, respectively ( $\mathrm{p}=0.005)$. On the other hand, the mean values of 'sentences' for study children aged $30-<48$ months was $(2.50 \pm 0.58 \& 1.5 \pm 0.71)$ respectively in the intervention and control groups ( $\mathrm{p}=0.132)$.

Table 4b: Expressive language development for children regarding their age, according to nurses' report.

\begin{tabular}{|c|c|c|c|c|}
\hline & \multirow[t]{2}{*}{$\begin{array}{c}\text { Experimental Mean } \\
\pm \text { SD }\end{array}$} & \multirow[t]{2}{*}{$\begin{array}{c}\text { Control Mean } \\
\pm \text { SD }\end{array}$} & \multicolumn{2}{|c|}{ T test } \\
\hline & & & $\mathbf{T}$ & P-value \\
\hline \multicolumn{5}{|c|}{ First words total score for children at age of $12-<19$ months } \\
\hline Pre & $20.7 \pm 5.1$ & $19.5 \pm 0.7$ & 0.323 & 0.754 \\
\hline Post & $42.8 \pm 7.9$ & $38.5 \pm 0.7$ & 0.743 & 0.475 \\
\hline \multicolumn{5}{|c|}{ Word combinations for children at age of $19-<30$ months } \\
\hline Pre & $1.24 \pm 0.43$ & $1.14 \pm 0.38$ & 0.571 & 0.57 \\
\hline Post & $1.96 \pm 0.19$ & $1.71 \pm 0.45$ & 2.596 & $* 0.012$ \\
\hline \multicolumn{5}{|c|}{ Sentences for children at age of $30-<48$ months } \\
\hline Pre & $1.75 \pm 0.5$ & $1.5 \pm 0.7$ & 0.516 & 0.633 \\
\hline Post & $1.75 \pm 0.5$ & $1.5 \pm 0.7$ & 0.516 & 0.633 \\
\hline
\end{tabular}

*statistically significant $(p=<0.05)$. 
Table 5: Comparing experimental and control groups across the six weeks period.

\begin{tabular}{|c|c|c|c|c|c|c|c|}
\hline & \multicolumn{6}{|c|}{ Months } & \multirow{2}{*}{$\begin{array}{c}\text { ANOVA } \\
\text { Test }\end{array}$} \\
\hline & 1 & 2 & 3 & 4 & 5 & 6 & \\
\hline \multicolumn{8}{|c|}{$\begin{array}{l}\begin{array}{l}\text { First words total score for children at age of } 12- \\
<19 \text { months }\end{array}\end{array}$} \\
\hline \multirow[t]{2}{*}{ Experimental } & $25.2 \pm 5.6$ & $28.6 \pm 6.2$ & $32.2 \pm 6.9$ & $35.4 \pm 7.5$ & $38.1 \pm 8.1$ & $44.2 \pm 8.1$ & $F=9.161$ \\
\hline & & & & & & & ${ }^{* *} \mathrm{P}<0.001$ \\
\hline \multirow[t]{2}{*}{ Control } & $24.0 \pm 1.4$ & $28.0 \pm 1.4$ & $30.5 \pm 0.7$ & $33.0 \pm 1.4$ & $35.5 \pm 0.7$ & $39.5 \pm 0.7$ & $\mathrm{~F}=48.440$ \\
\hline & & & & & & & ${ }^{* *} \mathrm{P}<0.001$ \\
\hline \multicolumn{8}{|c|}{$\begin{array}{l}\text { Word combinations for children at age of } 19-<30 \\
\text { months }\end{array}$} \\
\hline \multirow[t]{2}{*}{ Experimental } & 1.37 & 1.48 & 1.57 & 1.64 & 1.75 & 1.96 & $F=11.944$ \\
\hline & \pm 0.49 & \pm 0.50 & \pm 0.49 & \pm 0.48 & \pm 0.43 & \pm 0.19 & ${ }^{* *} \mathrm{P}<0.001$ \\
\hline \multirow[t]{2}{*}{ Control } & 1.29 & 1.43 & 1.43 & 1.57 & 1.71 & 1.71 & $\mathrm{~F}=0.800$ \\
\hline & \pm 0.49 & \pm 0.53 & \pm 0.53 & \pm 0.53 & \pm 0.45 & \pm 0.45 & $\mathrm{P}=0.557$ \\
\hline \multicolumn{8}{|c|}{ Sentences for children at age of $30-<48$ months } \\
\hline \multirow[t]{2}{*}{ Experimental } & 1.5 & 1.5 & 1.5 & $1.65 \pm 0.4$ & $1.75 \pm 0.3$ & $1.75 \pm 0.3$ & $\mathrm{~F}=0.339$ \\
\hline & \pm 0.50 & \pm 0.50 & \pm 0.50 & & & & $\mathrm{P}=0.882$ \\
\hline \multirow[t]{2}{*}{ Control } & 1.5 & 1.5 & 1.5 & 1.58 & 1.58 & 1.65 & $F=0.023$ \\
\hline & \pm 0.70 & \pm 0.70 & \pm 0.70 & \pm 0.50 & \pm 0.40 & \pm 0.40 & $\mathrm{P}=0.998$ \\
\hline
\end{tabular}

${ }^{* *}$ High statistically significant $(p=<0.001)$.

Table 6a: Expressive language development (ELD) for children regarding their sex, according to mothers' report.

\begin{tabular}{|c|c|c|c|c|}
\hline & \multirow[t]{2}{*}{ Girls Mean \pm SD } & \multirow[t]{2}{*}{ Boys Mean \pm SD } & \multicolumn{2}{|c|}{ T test } \\
\hline & & & $\mathbf{T}$ & $\mathbf{P}$ \\
\hline \multicolumn{5}{|c|}{ First words total score for children at age of $12-<19$ months } \\
\hline \multicolumn{5}{|l|}{ Experimental } \\
\hline Pre & $22.8 \pm 5.9$ & $21.7 \pm 5.2$ & 0.306 & 0.767 \\
\hline Post & $51.8 \pm 8.3$ & $37.2 \pm 8.5$ & 2.685 & $*^{*} 0.028$ \\
\hline \multicolumn{5}{|l|}{ Control } \\
\hline Pre & - & - & - & - \\
\hline Post & - & - & - & - \\
\hline \multicolumn{5}{|c|}{ Word combinations for children at age of $19-<30$ months } \\
\hline \multicolumn{5}{|l|}{ Experimental } \\
\hline Pre & $1.40 \pm 0.52$ & $1.25 \pm 0.38$ & 1.169 & 0.248 \\
\hline Post & $2.05 \pm 0.20$ & $0.85 \pm 0.23$ & 2.961 & $* 0.005$ \\
\hline \multicolumn{5}{|l|}{ Control } \\
\hline Pre & $1.50 \pm 0.58$ & $1.33 \pm 0.58$ & 0.378 & 0.721 \\
\hline Post & $2.25 \pm 0.50$ & $1.17 \pm 0.58$ & 2.651 & $* 0.045$ \\
\hline \multicolumn{5}{|c|}{ Sentences for children at age of $30-<48$ months } \\
\hline Experimental & $2.0 \pm 0.2$ & $1.5 \pm 0.58$ & 1.155 & 0.312 \\
\hline \multicolumn{5}{|l|}{ Pre } \\
\hline Post & $2.9 \pm 0.2$ & $1.6 \pm 0.58$ & 2.931 & $* 0.043$ \\
\hline
\end{tabular}

*statistically significant $(p=<0.05)$.

Table 6b: Expressive language development for children regarding their sex, according to nurses' report.

\begin{tabular}{|c|c|c|c|c|}
\hline & Girls Mean \pm SD & Boys Mean \pm SD & T test & T \\
\hline First words total score for children at age of $\mathbf{1 2}-<\mathbf{1 9}$ months & & & & \\
\hline Experimental & & & & \\
\hline Pre & $22.8 \pm 5.9$ & $21.7 \pm 5.2$ & 0.306 & 0.767 \\
\hline
\end{tabular}




\begin{tabular}{|c|c|c|c|c|}
\hline Post & $51.8 \pm 8.3$ & $37.2 \pm 8.5$ & 2.685 & $* 0.028$ \\
\hline \multicolumn{5}{|l|}{ Control } \\
\hline Pre & - & - & - & - \\
\hline Post & - & - & - & - \\
\hline \multicolumn{5}{|c|}{ Word combinations for children at age of $19-<30$ months } \\
\hline \multicolumn{5}{|l|}{ Experimental } \\
\hline Pre & $1.37 \pm 0.53$ & $1.21 \pm 0.38$ & 1.237 & 0.222 \\
\hline Post & $1.99 \pm 0.38$ & $1.67 \pm 0.45$ & 2.437 & $* 0.018$ \\
\hline \multicolumn{5}{|l|}{ Control } \\
\hline Pre & $1.46 \pm 0.61$ & $1.27 \pm 0.62$ & 0.405 & 0.702 \\
\hline Post & $2.15 \pm 0.48$ & $1.14 \pm 0.53$ & 2.642 & $* 0.046$ \\
\hline \multicolumn{5}{|c|}{ Sentences for children at age of $30-<48$ months } \\
\hline Experimental & $1.99 \pm 0.21$ & $1.51 \pm 0.59$ & 1.153 & 0.313 \\
\hline \multicolumn{5}{|l|}{ Pre } \\
\hline Post & $2.91 \pm 0.21$ & $1.62 \pm 0.59$ & 2.928 & $* 0.044$ \\
\hline
\end{tabular}

*statistically significant $(p=<0.05)$,

Table 7: Comparing child's (language delay severity) response in experimental and control groups to nurse and parent or care giver.

\begin{tabular}{|c|c|c|c|c|c|c|}
\hline & \multicolumn{2}{|c|}{ Experimental $(n=68)$} & \multicolumn{2}{|c|}{ Control $(\mathrm{n}=11)$} & \multicolumn{2}{|c|}{ Chi Square Test } \\
\hline & & & & & $\mathrm{X}_{2}$ & $\mathrm{P}$ \\
\hline \multicolumn{7}{|l|}{ Pre } \\
\hline Mild delay & 16 & 23.5 & 4 & 36.4 & & \\
\hline Moderate delay & 31 & 45.6 & 5 & 45.5 & & \\
\hline Severe delay & 21 & 30.9 & 2 & 18.2 & 1.141 & 0.565 \\
\hline \multicolumn{7}{|l|}{ Post } \\
\hline Mild delay & 35 & 51.5 & 2 & 18.2 & & \\
\hline Moderate delay & 22 & 32.4 & 4 & 27.3 & & \\
\hline Severe delay & 11 & 16.2 & 5 & 54.5 & 6.294 & ${ }^{*} 0.043$ \\
\hline
\end{tabular}

${ }^{*}$ statistically significant $(p=<0.05)$,

Expressive language development (ELD) for children regarding their ages, according to nurses' reports was illustrated in Table $4 \mathrm{~b}$. The mean values of the total score of 'first words' uttered by the study children aged12-<19 months were(42.8 \pm 7.9 \& 38.5 \pm 0.7$)$ in the experimental and control groups, respectively $(\mathrm{p}=0.475)$. In the study children aged $19-<30$ months, the mean values of word combinations were $(1.96 \pm 0.19 \& 1.71 \pm 0.45)$ in the intervention and control groups $(\mathrm{p}=0.012)$, while the mean value of sentences for children aged $30-<48$ months was $(1.75 \pm 0.5$ \& $1.5 \pm 0.7)$ respectively in both groups $(\mathrm{p}=0.633)$. Table 5 showed that comparing experimental and control groups across the six weeks' period, there was a statistically significant improvement $(p=<0.001)$ in first words total score for study children aged 12$<19$ months across six weeks in both groups In addition, towards combinations for study children aged 19-<30 months, a statistically significant improvement $(\mathrm{p}=<0.001)$ was observed in experimental group compared with no statistical significant improvement $(p=0.557)$ in the control group. Among study children aged $30-<48$ months, no statistical significant improvement was observed in the experimental and control groups.

Table $6 \mathrm{a}$ showed the mean values of the total score of first words for study children aged $12-<19$ months were $(51.8 \pm 8.3$ \&
$37.2 \pm 8.5$ ) in girls and boys in the experimental and control groups, respectively $(\mathrm{p}=0.028)$.The mean values of word combinations for children aged $19-<30$ months were $2.05 \pm 0.20 \& 0.85 \pm 0.23$ in girls and boys, respectively in the experimental group ( $\mathrm{p}=0.005)$, and $(2.25 \pm 0.50 \& 1.17 \pm 0.58)$ in girls and boys, respectively in the control group $(\mathrm{p}=0.045)$. The mean value of sentences for children aged $30-<48$ months was $(2.9 \pm 0.2 \& 1.6 \pm 0.58)$ in girls and boys, respectively in the experimental group $(p=0.043)$. Table $6 b$ showed the mean values of the first words total score for the study children aged $12-<19$ months were(50.25 $\pm 8.22 \& 36.83 \pm 8.42)$ in girls and boys, respectively in the experimental group $(\mathrm{p}=0.038)$. The mean values of word combinations for the study children aged $19-<30$ months were $(1.99 \pm 0.38 \& 1.67 \pm 0.45)$ respectively in girls and boys, respectively in the experimental group $(\mathrm{p}=0.018)$, and $(2.15 \pm 0.48 \& 1.14 \pm 0.53)$ respectively in girls and boys, respectively in the control group $(\mathrm{p}=0.046)$. The mean values of sentences for the children aged $30-<48$ months was $(2.91 \pm 0.21 \& 1.62 \pm 0.59)$ respectively in girls and boys, respectively, in the experimental group ( $\mathrm{p}=0.044$ ). Table 7 showed that when the parents and nurses' responses for the study children's language delay severity across the experimental and control groups were compared, approximately one third $(30.9 \%)$ of the study children in the experimental group 
had severe language delay pre-intervention and this decreased to $16.2 \%$ of children, post-intervention $(\mathrm{p}=0.043)$ Figure 1 . On the other hand, less than one quarter $(18.2 \%)$ of the study children in the control group had severe language delay pre-intervention, this result increased to about half ( $54.5 \%)$ of children post-intervention $(\mathrm{p}=<0.043)$.

\section{Aduped for Language Development Survey}

Please circle each word that your child says SPONTANEOUSLY (not just imitates or understands) and that you have heard at least 3 times. It's OK to count words that aren't pronounced clearly or are in "baby talk" ("baba" for bottle). There is space in each section to list other words your child uses.

\begin{tabular}{|c|c|c|c|c|c|c|}
\hline $\begin{array}{l}\text { FOODS } \\
\text { apole }\end{array}$ & $\begin{array}{l}\text { CLOTHES } \\
\text { belt }\end{array}$ & $\begin{array}{l}\text { ANIMLALS } \\
\text { alligator }\end{array}$ & $\begin{array}{l}\text { ACTIONS } \\
\text { breakfast }\end{array}$ & HOUSEHOLD & PERSONAL & OTHER \\
\hline $\begin{array}{l}\text { apple } \\
\text { banana }\end{array}$ & boots & $\begin{array}{l}\text { amgitor } \\
\text { bear }\end{array}$ & $\begin{array}{l}\text { Oreakatast } \\
\text { bring }\end{array}$ & $\begin{array}{l}\text { bathrtub } \\
\text { bed }\end{array}$ & bath & $\mathrm{A}, \mathrm{B}, \mathrm{C}$, etc. \\
\hline $\begin{array}{l}\text { banana } \\
\text { bread }\end{array}$ & coat & bee & catch & bed & brush & $1,2,3$, etc \\
\hline $\begin{array}{l}\text { Oread } \\
\text { butter }\end{array}$ & diaper. & bird & & blanket & comb & animal sounds \\
\hline butter & & Oard & clap & bottle & glasses & away \\
\hline cake & dress & bug & close & bow & key & boo-boo \\
\hline candy & gloves & bunny & come & chair & money & bye-bye \\
\hline cereal & hat & camel & cough & clock & paper & down \\
\hline cheese & jacket & cat & cry & crib & pen & excuse me \\
\hline chips & mittens & chicken & cut & cup & pencil & here \\
\hline coffee & pajamas & cow & dance & doot & penny & hi, hello \\
\hline cookie & pants & deer & dinner & floor & tissue & in \\
\hline crackers & shirt & dinosane & eat & fork & toothbrush & me \\
\hline drink & shoes & $\operatorname{dog}$ & feed & fridge & umbrella & meow \\
\hline egg & slippers & duck & finish & glass & watch & my \\
\hline food & sneakers & elephant & fix & knife & & myself \\
\hline grapes & snowsuit & fish & get & light & & night-night \\
\hline gum & socks & frog & gimme & mirror & & no \\
\hline hamburger & sweater & giraffe & give & pillow & TOYS & off \\
\hline hot dog & tights & gorilla & go & plate & ball & on \\
\hline ice cream & & hippo & have & potty & balloon & out \\
\hline juice & & horse & help & radio & blocks & please \\
\hline meat & MODIFIERS & kitten & hit & room & book & shut up \\
\hline milk & all done & lizard & hug & $\operatorname{sink}$ & bubbles & thank you \\
\hline orange & all gone & monkey & jump & soap & crayons & there \\
\hline pizza & bad & mouse & kick & spoon & doll & under \\
\hline pop & big & pig & kiss & stairs & picture & up \\
\hline pretzel & black & puppy & knock & table & present & welcome \\
\hline raisins & blue & rabbit & look & telephone & slide & what \\
\hline soda & broken & sheep & love & towel & swing & where \\
\hline soup & clean & snake & lunch & trash & teddy bear & why \\
\hline spaghetti & cold & squirrel & make & $T$ & & yes \\
\hline toast & dark & tiger & nap & window & & you \\
\hline \multirow[t]{4}{*}{ water } & dirty & turkey & open & & & yum, yum \\
\hline & dry & turtle & outside & & VEHICLES & \\
\hline & good & zebra & pattycake & & bike & \\
\hline & green & & peekaboo & BODY PARTS & boat & \\
\hline PEOPLE & happy & . & peepee & arm & bus & \\
\hline aunt & heavy & & poop & belly button & car & \\
\hline baby & hot & & push & bottom & motorcycle & \\
\hline boy & hungry & OUTDOOR & read & chin & plane & \\
\hline brother & little & cloud & ride & ear & stroller & \\
\hline daddy & mine & flower & run & elbow & train & \\
\hline doctor & more & grass & see & eye & truck & \\
\hline girl & nice & house & show & face & & \\
\hline grandma & orange & moon & shut & finger & & \\
\hline grandpa & pretty & rain & sing & foot & & \\
\hline lady & purple & rock & sit & hair & PLACES & FAVORITE TV \\
\hline $\operatorname{man}$ & red & sidewalk & sleep & hand & church & MOVIEAOOK \\
\hline mommy & stinky & sky & stop & knee & home & CHARACTERS \\
\hline own name & that & snow & take & leg & hospital & \\
\hline pet name & this & star & throw & mouth & library & \\
\hline sister & tired & stick & tickle & neck & park & \\
\hline uncle & wet & street & walk & nose & school & \\
\hline & white & $\operatorname{sun}$ & want & teeth & store & \\
\hline & yellow & tree & wash & thumb & & \\
\hline & yucky & $\longrightarrow$ & yell & toe & & \\
\hline
\end{tabular}

Does your child combine two or more words into phrases? (e.g. "more cookie," "car bye-bye," etc.)? Yes No On the back of this page, please write down three of your child's longest and best phrases or sentences. 


\section{Discussion}

To our knowledge, this is the first study reporting the effects of parents' involvement language intervention programmes on speech language delay in Egyptian toddlers. Of the 79 toddlers enrolled into the study, more than three quarter of the study children $(79.4 \%)$ randomly assigned to the experimental group were within the age group of $19-<30$ months. This is not surprising given that this is the peak age in which speech language delay has been widely reported in previous studies. [22,23,24] The mean scores for girls in all domains of LDS were greater than boys and reached statistical significance. Previous findings on the role of gender in speech language disorder has been inconclusive; while some studies reported association of gender, others reported no influence of gender on speech language delay in children. Our findings contrast with study conducted by Akbari and colleagues [25] who reported that the risk of developmental delay is higher in boys. Conversely, Kerstjens, et al. [26] reported about 2-5 higher increased risk in girls compared to boys while Piek, et al. [27] reported that gender had no influence on developmental delay, consistent with Kapci, et al. [28] who reported no significant differences between male and female children in their study. Despite these conflicting findings, experts have reported an increased tendency towards speech language delay in male children might be related to X-linked disorders more frequently seen in male children [29].

Our study showed that approximately two thirds of the study mothers $(66.2 \%)$ were unemployed and in low socio-economic strata, with $70.6 \%$ of the mothers in the experimental group having an average annual income. This resonates with previous findings which reported association of low maternal education and socioeconomic level with speech language delay $[23,30]$. Plausible reason cited for this was the financial challenges posed by low educational and socio-economic status which limit the purchasing power of the mothers to provide necessary materials required to nurture and support child's speech development. Majority of the study mothers $(63.2 \%)$ in the experimental group were in the age group of 20-40 years while more than one quarter $(27.9 \%)$ had family history of language delay. This is consistent with findings which reported increased risk of development delay in children delivered by mothers at ages above 35 years [31,32]. Although, we found that about $40 \%$ of the study children in the experimental group had a history of ear infection compared to about $20 \%$ in the control group, this finding supports previous studies which reported similar observations [2,29]

Our study has a couple of strengths and limitations. The quasiexperimental design of this study made it possible to demonstrate the effect of parents' involvement interventions in late talking toddlers. We also adapted and validated the LDS tool [11] to objectively assess the improvement of the study children following exposure to a battery of interventions that actively were facilitated by study mothers. This tool developed and used amongst ethnolinguistically diverse South African toddlers [11] was successfully adapted and validated cross-culturally to establish the relevance of the vocabulary of (LDS) in Egyptian late talking toddlers.
The relatively small sample size in our study is a major limitation in generalizing the findings to the population of Egyptian toddlers with speech delay. Also, inability to monitor the level of compliance of the study mothers and depending solely on their self-reports about the performance of the children may over or under-estimate the actual speech status of the children. Nevertheless, our study has contributed to the small but important body of knowledge on the relevance of parents' involvement intervention in late talking toddlers.

\section{Conclusion}

Our study has demonstrated that parents' reports provided some useful ideas about their involvement and its positive effect in terms of language development of their late-talking toddlers. We also found that parent involvement in language interventional/ speech therapy program is a viable model for promoting short-term developmental progress in late-talking toddlers. Further studies using randomized controlled design are needed for evaluation and long-term follow-up of this important strategy for children with speech language delay.

\section{References}

1. Meschino WS (2003) The child with developmental delay: An approach to etiology. Paediatr Child Health 8(1): 16-19.

2. Demirci A, Kartal M (2016) The prevalence of developmental delay among children aged 3-60 months in Izmir, Turkey. Child Care Health and Dev 42(2): 213-219.

3. Sidhu M, Malhi P, Jerath J (2013) Early language development in Indian children: A population-based pilot study. Ann Indian Acad Neurol 16(3): 371-375.

4. Rosenbaum S, Simon P (2020) Speech and language disorders in children: Implications for the social security administration's supplemental security income program. Washington (DC): National Academies Press (US); 2016 Apr 6. 2, Childhood Speech and Language Disorders in the General U.S. Population, USA.

5. Law J, Boyle J, Harris F, Harkness A, Nye C (1998) Screening for speech and language delay: a systematic review of the literature. Health technology assessment (Winchester, England) 2(9): 1-184.

6. Bleses D, Vach W, Jørgensen RN, Worm T (2010) The internal validity and acceptability of the Danish SI-3: A language-screening instrument for 3-year-olds. J Speech Lang Hear Res 53(2): 490-507.

7. Rijlaarsdam J, Stevens GM, van Ende J, Hofman A, Jaddoe VV, et al. (2013) Economic disadvantage and young children's emotional and behavioral problems: Mechanisms of risk. J Abnorm Child Psychol 41(1): 125-137.

8. Ward S (1999) An investigation into the effectiveness of an early intervention method for delayed language development in young children. Int J Lang Commun Disord 34(3): 243-264.

9. Rossetti LM (2001) Communication intervention: Birth to three, $2^{\text {nd }}$ Edition. Singular-Thompson Learning, Canada.

10. Rvachew S, Bernhardt BM (2010) Clinical implications of dynamic systems theory for phonological development. Am J Speech Lang Pathol 19(1): 34-50.

11. Gonasillan A, Bornman J,Harty M (2013) Vocabulary used by ethno-linguistically diverse South African toddlers: A parent report using the language development survey. S Afr J Commun Disord 60: 10-15.

12. Mostafa E, Ahmed M (2018) Public awareness of delayed language development in Upper Egypt. The Egyptian Journal of Otolaryngology 34(1): 94-102. 
13. Zaki Ewiss MA, Abdelgawad F, Elgendy A (2019) School educational policy in Egypt: Societal assessment perspective. Journal of Humanities and Applied Social Sciences 1(1): 55-68.

14. Egypt: Early childhood care and education (ECCE) programs.

\section{AL-ISKANDARIYAH_Governorate, Egypt.}

16. Rescorla L, Alley A (2001) Validation of the Language Development Survey (LDS): A parent report tool for identifying language delay in toddlers. J Speech Lang Hear Res 44(2): 434-445.

17. Papaeliou CF, Rescorla LA (2011) Vocabulary development in Greek children: A cross-linguistic comparison using the language development survey. J Child Lang 38(4): 861-887.

18. El-Gilany A, El-Wehady A, El-Wasify M (2012) Updating and validation of the socioeconomic status scale for health research in Egypt. East Mediterr Health J 18(9): 962-968.

19. Fahmy S, El-Sherbini AF (1983) Determining simple parameters for social classifications for health research. Bulletin of the High Institute of Public Health 13: 95-108.

20. Average Salary in Egypt 2020.

21. Bates E, Marchman V, Thal D, Fenson L, Dale P, et al. (1994) Development and stylistic variation in the composition of early vocabulary. J Child Lang 21(1): 85-123.

22. Flusberg HT, Rogers S, Cooper J, Landa R, Lord C, et al. (2009) Defining spoken language benchmarks and selecting measures of expressive language development for young children with autism spectrum disorders. J Speech Lang Hear Res 52(3): 643-652.

23. Koller H, Lawson K, Rose SA, Wallace I, McCarton C (1997) Patterns of cognitive development in very low birth weight children during the first six years of life. Pediatrics 99(3): 383-389.
24. Law J, Boyle J, Harris F, Harkness A, Nye C (2000) Prevalence and natural history of primary speech and language delay: findings from a systematic review of the literature. Int J Lang Commun Disord 35(2): 165-188.

25. Amir Ali Akbari S, Montazeri S, Torabi F, Amiri S, et al. (2012) Correlation between anthropometric indices at birth and developmental delay in children aged 4-60 months in Isfahan, Iran. Int J Gen Med 5: 683-687.

26. Kerstjens JM, Bos AF, Ten Vergert EM, de Meer G, Butcher PR, et al. (2009) Support for the global feasibility of the ages and Stages questionnaire as developmental screener. Early Human Development 85(7): 443-447.

27. Piek JP, Dawson L, Smith LM, Gasson N (2008) The role of early fine and gross motor development on later motor and cognitive ability. Human Movement Science 27(5): 668-681.

28. Kapci EG, Kucuker S, Uslu RI (2010) How applicable are ages and stages questionnaires for use with Turkish children? Topics in Early Childhood Special Education 30(3): 176-188.

29. Srour M, Mazer B, Shevell MI (2006) Analysis of clinical features predicting etiologic yield in the assessment of global developmental delay. Pediatrics 118(1): 139-145.

30. Pilz EM, Schermann LB (2007) Environmental and biological determinants of neuropsychomotor development in a sample of children in Canoas/RS. Ciencia Saude Colet 12(1): 181-190.

31. Paulson RJ, Boostanfar R, Saadat P, Mor E, Tourgeman DE, et al. (2002) Pregnancy in the sixth decade of life: Obstetric outcomes in women of advanced reproductive age. Jama 288(18): 2320-2323.

32. Ziadeh S, Yahaya A (2001) Pregnancy outcome at age 40 and older. Arch Gynecol Obstet 265(1): 30-33. 